\title{
Seismic analysis of aircraft accidents
}

\author{
Matti Tarvainen $^{1 *}$, Outi Valtonen ${ }^{1}$, Eystein S. Husebye ${ }^{2}$, Björn Lund $^{3}$ \\ ${ }^{1}$ Institute of Seismology University of Helsinki, Helsinki, Finland; ${ }^{*}$ Corresponding Author: Matti.Tarvainen@helsinki.fi \\ ${ }^{2}$ BCCS, UNI Research, Bergen, Norway \\ ${ }^{3}$ Department of Geosciences, Uppsala University, Uppsala, Sweden
}

Received 11 April 2013; revised 12 May 2013; accepted 19 May 2013

Copyright (C) 2013 Matti Tarvainen et al. This is an open access article distributed under the Creative Commons Attribution License, which permits unrestricted use, distribution, and reproduction in any medium, provided the original work is properly cited.

\begin{abstract}
Seismic records from Finnish and Swedish stations were analyzed for a study of two aircraft accidents in Finland and Sweden. A Hornet F-18 fighter crashed in central Finland, and analysis of recorded impact signals from 7 nearby seismic stations yielded in a crash location only 4 $\mathrm{km}$ in error. An estimated magnitude (ML) of 0.5 units gave an impact velocity of $335 \mathrm{~m} / \mathrm{sec}(1200$ $\mathrm{km} / \mathrm{h}$ ), which was in excellent agreement with that reported by the Finnish Air Force. A Norwegian Hercules transport plane crashed in foul weather near the summit of Mt. Kebnekaise, NW Sweden. Both seismic and infrasound signals were weak, and in our interpretation, this implied that the Hercules aircraft had a less steep impact angle against the mountain. We also examined seismic analyses of other spectacular air accidents like that of Lockerbie, UK in 1988, and terrorist aircraft attacks on September $11^{\text {th }}, 2001$ in the USA. Likewise, accidents at sea, such as the sinking of the Russian submarine Kursk in the Barents sea in 2000, and the freighter M/S Rocknes near Bergen in 2004, were recorded and analyzed seismically. In this study, we demonstrated that it was feasible to use seismic registrations to locate impact sites, and to define the exact time of such accidents. Also, negative evidence, i.e., lack of seismic recordings, may provide some information of such accidents and their consequences.
\end{abstract}

Keywords: Seismology; Monitoring; Air Accidents; Maritime Accidents

\section{INTRODUCTION}

Analysis of seismic records enables us to detect and recognize sources of elastic waves traveling in the Earth's crust. Traditionally, such observations are restricted to earthquake signals, but many other types of sudden dislocations generate seismic waves, including mining and nuclear explosions, supersonic flights, building collapses, and explosions at sea. Advanced methods are used to track and locate almost any source, which emits seismic recordable signals in the Earth's crust. Following the September $11^{\text {th }}, 2001$ terrorist attack on the WTC towers in New York and on the Pentagon in Washington DC, the accurate timing of impacts and of building collapses were determined by analysis of registrations at nearby seismograph stations [1]. The accidental sinking of the nuclear submarine Kursk in the Barents Sea was Registered at Fennoscandian stations, and was initially reported as such [2]. With the ever-increasing number of modern highly sensitive seismic stations being deployed globally e.g. [3], more and more signals stemming from cultural activities will be recorded, and will occasionally provide clues to different kind of accidents.

In this paper we present an analysis of recent seismically recorded accidents, which demonstrates that such information may be useful in accident and rescue investigations. Archived seismic data are easily available, and are freely accessible for independent analyses and conclusions.

\section{AIRCRAFT IMPACTS AS SEISMIC SOURCE}

Seismic signals associated with impacts of aircraft or meteorites are weak, having ML-magnitudes of less than 2. Consequently, only few modern stations can detect such signals, and seldom at distances beyond 200 kilometers. However, if such recordings are available, they enable one to calculate a bearing (azimuth) towards the source, and then its geographical location or epicenter to the nearest $4 \mathrm{~km}$.

We may even extract source information from seismic recordings generated by the terminal velocity of a crashing aircraft. In cases of ship accidents, recordings of sig- 
nals and occasionally of bubble pulses, are telling evidence of such disasters. Below we outline a procedure for calculating the aircraft's terminal velocity, regard following the approach in [4]. From nuclear test ban studies, the magnitude $m_{b}$ (body wave) is known to be a function of yield for underground explosions of varying sizes, and of site environments [5]:

$$
m_{b}=4.45+0.75 \log (Y),
$$

where $Y$ is given in kilotons $\left(1 \mathrm{kt}=4.2 \times 10^{12} \mathrm{~J}\right)$. The relative partitioning of nuclear explosion energy into seismic waves was calculated [6], and obtained a coupling factor $e_{n}=5 \times 10^{-3}$. Obviously, the coupling efficiency of explosive impacts will be smaller, and experiments with artillery shells gave values between $e_{i}=2 \times$ $10^{-5}-1.3 \times 10^{-4}$, with an average $e_{i}=6 \times 10^{-5}$ [7-9]. In this regard, a crashing aircraft may generate signals similar to those of an artillery shell. From those signals we can estimate the impact coupling efficiency, and then the ratio between explosion and impact efficiency. In case of the F-18D crash, we obtained the ratio: $\varepsilon_{n} / \varepsilon_{i}=38$, and inserting this factor in Eq.1 we get

$$
m_{b}=4.45+0.75 \log \left[E_{i} /\left(\varepsilon_{n} / \varepsilon_{i}\right)\right] \text {. }
$$

\subsection{The Accident of the Finnish Air Force Hornet F-18D in 2010}

On January $21^{\text {st }}, 2010$ just before noon local time, the pilots lost control of the multirole fighter F-18D Hornet. The fighter began an uncontrolled and vigorous dive, and both pilots were forced to eject at an altitude of 4000 meters and simultaneously, the flight recording unit of the aircraft (i.e. black box) was released. The aircraft itself continued its nearly vertical dive, until it struck the ground in a rocky grove approximately 30 kilometers north of Tampere. A crater, which was a few meters wide, was formed at the site of impact.

The approximate time and location of the accident became fast available, allowing us to screen records and monitoring logs at the Finnish seismograph network center in Helsinki. Detections at several stations were clear, and instructive signals at Keuruu (KEF) and at Vaasa (VAF) are shown in Figure 1. The location of the crash site on the western Finland map is shown in Figure 2, and the location according to the seismic analysis is in Figure 3. From the obtained value of $m_{b}=0.5$, the aircraft's terminal velocity could be estimated using the Eq. 2 and presuming the mass of the Hornet to be 15,000

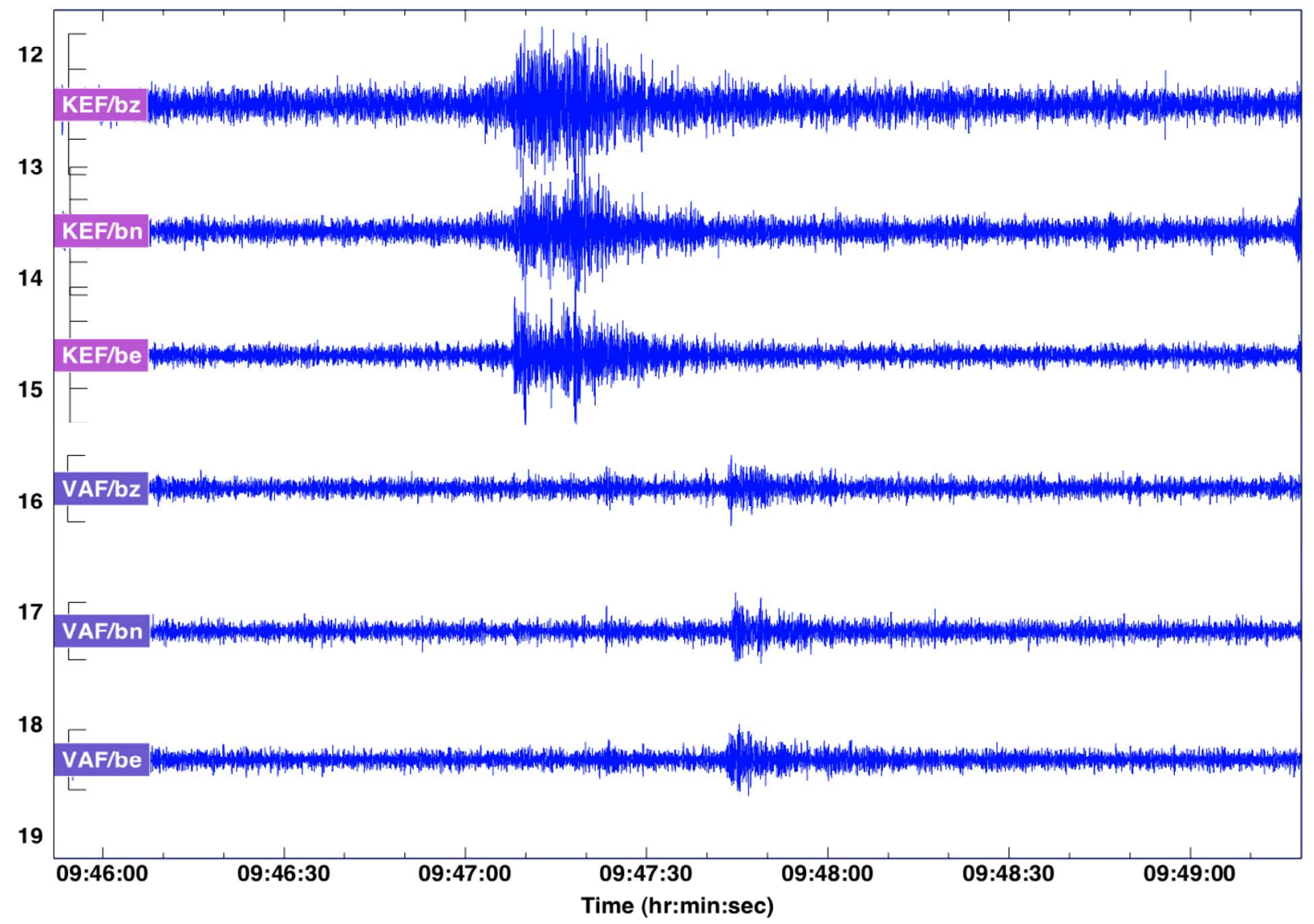

Figure 1. Seismic recordings of the F-18D crash in Juupajoki municipality. The upper three signals are from the station KEF ( $\Delta$ $=49 \mathrm{~km})$ and the lower three from the station $\operatorname{VAF}(\Delta=168 \mathrm{~km})$. Both stations have three-component broadband equipment. 


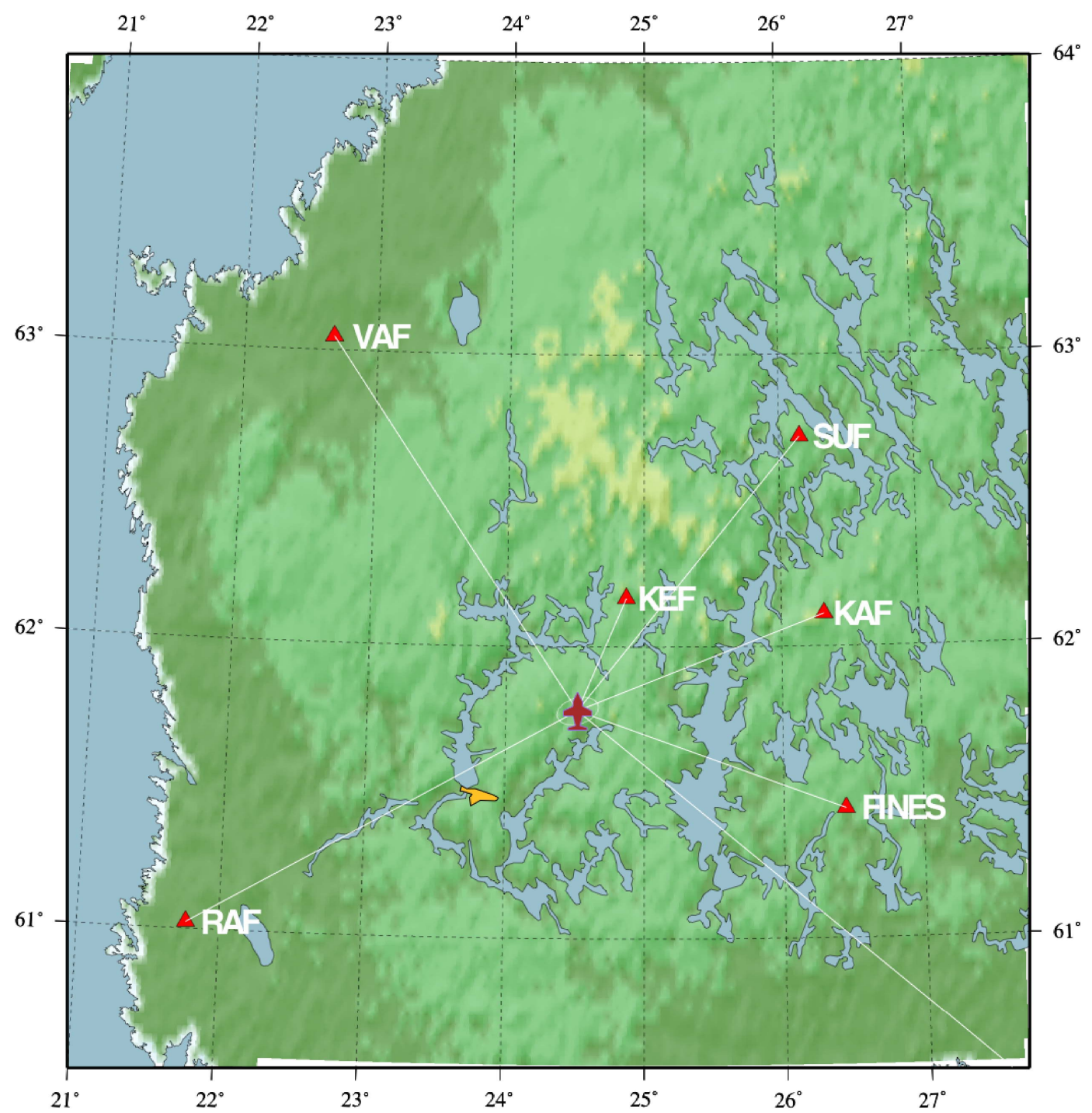

Figure 2. The map of western Finland showing the location of the Hornet's crash site. The seismic traces are shown by white thin lines. The ellipse of area $125 \mathrm{~km}^{2}$ with major and minor axis 8 and 4 kilometers, respectively around the aircraft symbol represents the location error of the analysis. Station VJF is outside the map, but its data were used in the work, as well.

$\mathrm{kg}$. The obtained velocity was approximately $335 \mathrm{~m} / \mathrm{s}$ $(1200 \mathrm{~km} / \mathrm{h}$, while the accident investigation commission reported a velocity $380 \mathrm{~m} / \mathrm{s}$ - close to our estimate), see also Figure 4. Since the "black box" monitoring device was ejected prior to impact, a more accurate estimate was not available.

\subsection{The Hercules Crash at Mt. Kebnekaise, Sweden in 2012}

On March $15^{\text {th }}, 2012$, a Hercules aircraft of the Norwegian Air Force bound for Kiruna, Sweden, crashed in foul weather near the peak of Mt. Kebnekaise.

The crash triggered avalanches, which covered debris scattered over a large area. After several months larger parts of the Hercules were found, including the tail fin and wing pieces, and at last the aircraft's "black box". The initial rescue mission was problematic due to bad weather, high altitude at 2000 meters and because the crash site could not be pinpointed. On the last leg, of its flight path, the plane disappeared from radar, but the exact crash time, as reported in the accident commission's report [10], was derived from the seismic records at the Swedish Nikkaluokta (NIK) station at a distance of 25 kilometers (Figure 5). The estimated $m_{b}$-magnitude was only 0.01 units, despite the Hercules mass of 40 tons, and a flight speed of $510 \mathrm{~km} / \mathrm{h}(150 \mathrm{~m} / \mathrm{s})$ when it crashed. These features may be considered as a sort of negative evidence, implying that the aircraft had hit the ground at a relatively low angle, and then disintegrated into thousands of fragments. Our physical argument here is that 


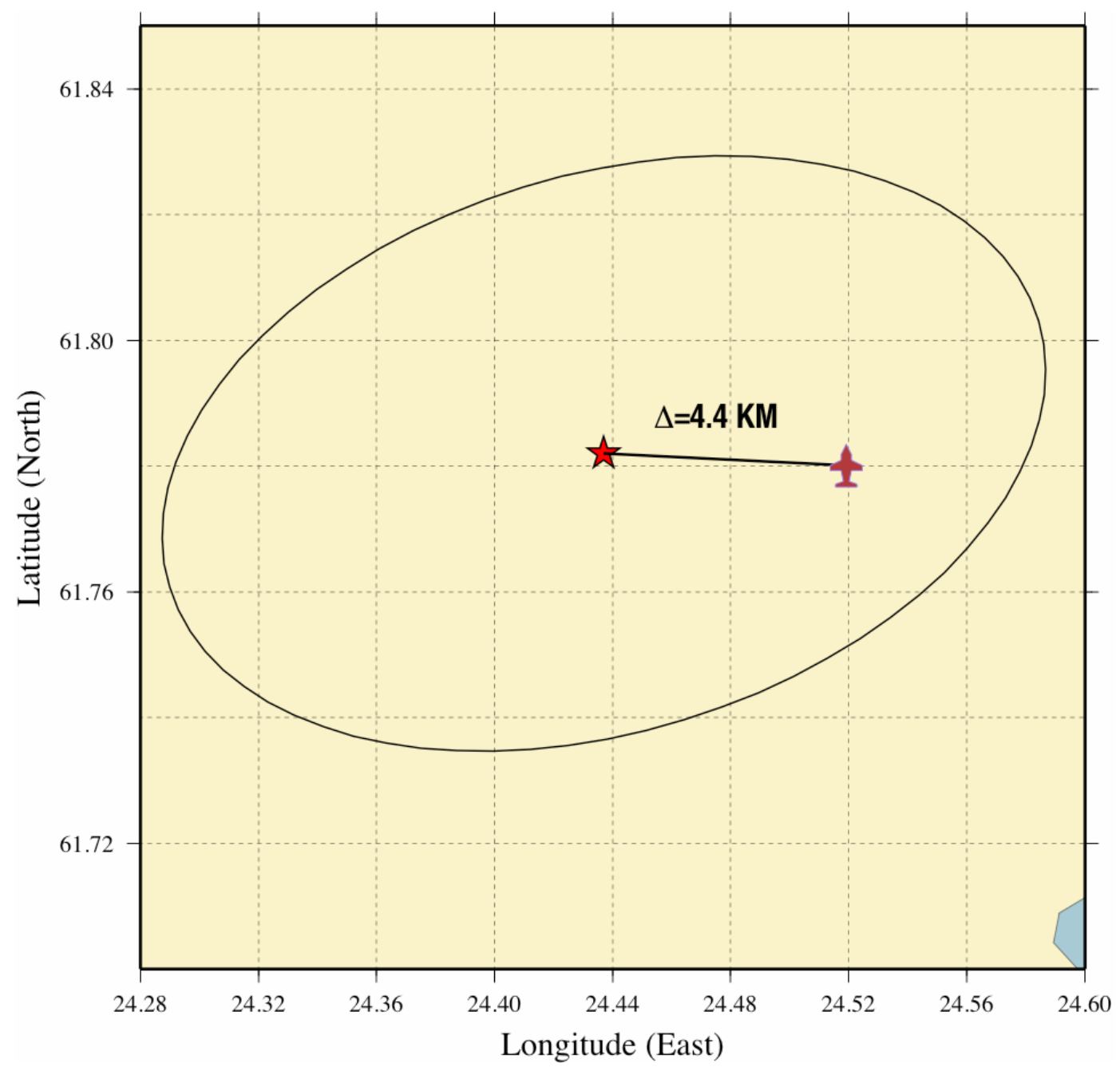

Figure 3. The more detailed picture of the Hornet's crash site location with the red asterisk presenting our location obtained from seismic registrations while the "aircraft" symbol represents that obtained by in situ observations.

the kinetic energy, given the above mass and speed values, would have been roughly $50 \%$ of that of the Finnish Hornet fighter, corresponding to a magnitude of 0.20 0.25 .

The lack of seismic observations gives a clue to the final stage of the Hercules approach to the Kiruna airport; it flew too low relative to the height of Mt. Kebnekaise and hit a rock wall at an angle of roughly 45 degrees, according to the Air Crash Commission. Our conclusions here were published prior to the report of the commission.

\subsection{Reanalysis of the Lockerbrie, UK Air Crash in 1988}

On December $21^{\text {st }}, 1988$ the Boeing 747-121 aircraft of PanAm transatlantic flight No. 103 was disabled by an explosive device over the Lockerbie village, Scotland. At about 5000 meters the plane disintegrated, and the wing section containing 91 tons of fuel exploded upon impact in the village. The seismic source in this case became a combination of wing section impact and kerosene explosion, and the resulting seismic signals were well recorded by the Eskdalemuir seismic array to the North.

An explosion crater of approximately 50 by 15 meters was generated by the ejection of about 1500 tons of earth. According to the British Geological Survey, the $m_{b^{-}}$ magnitude calculated from the registered signals was 1.6 units on the Richter scale.

Estimate of the total energy contents of the wing section, its exploding fuel load, and of the dislocated soil, using realistic coupling ratios, gave a value of impact energy close to $4200 \mathrm{MJ}$. This is equivalent to 1 ton of TNT, and hence giving an $m_{b}$-magnitude estimate of 1.8 in case of a well-coupled explosion. In other words, the seismic record may be used to estimate the energy of an impact at the aircraft crash site, and can hence contribute 


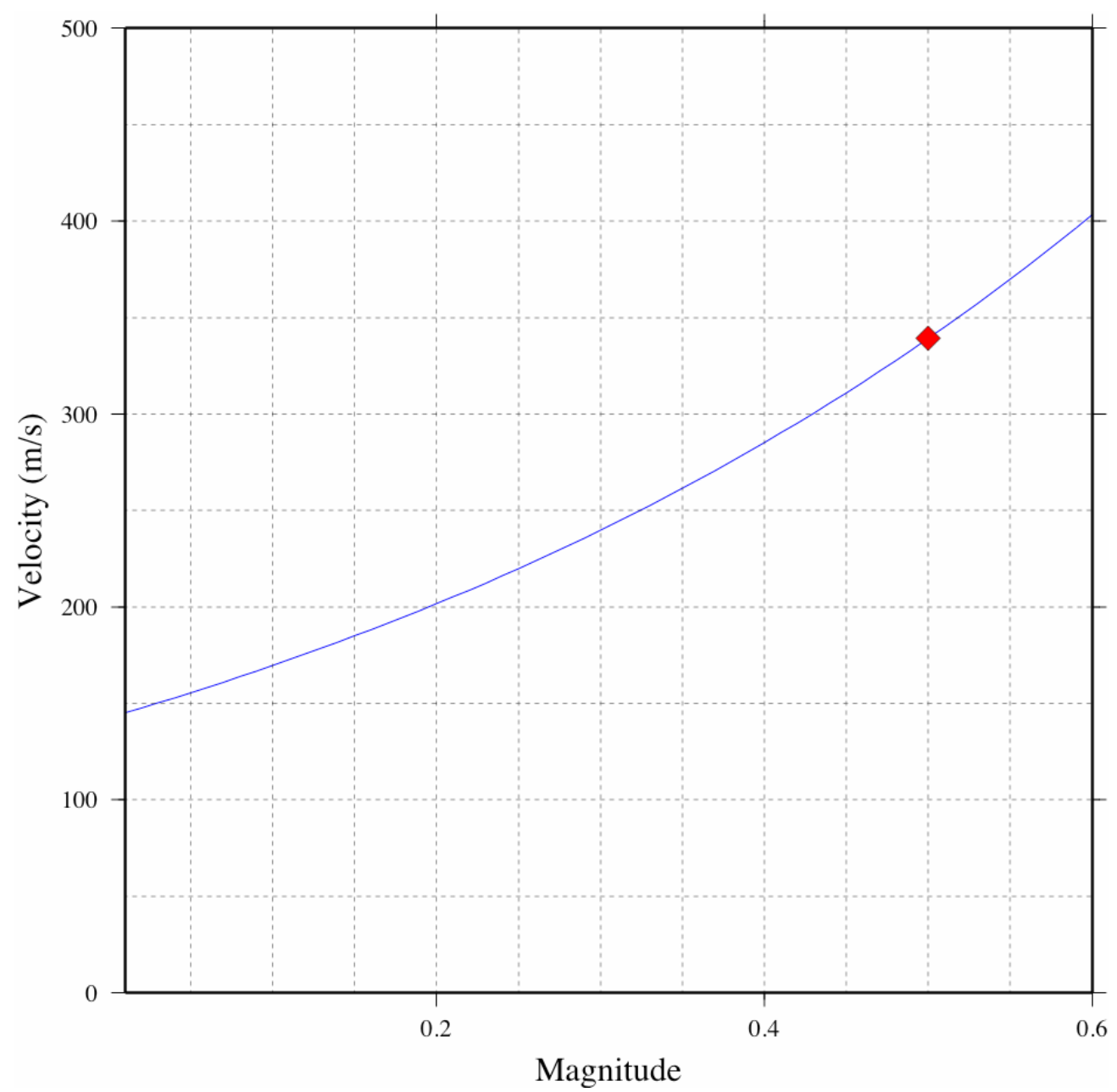

Figure 4. For this study the impact velocity is shown as a function of body wave magnitude $m_{b}$ and utilizing the Eq.2. The mass of the aircraft is set to $15,000 \mathrm{~kg}$, and the coupling efficiency ratio $e_{n} / e_{i}$ to 38. The red diamond shows the value obtained by our analysis.

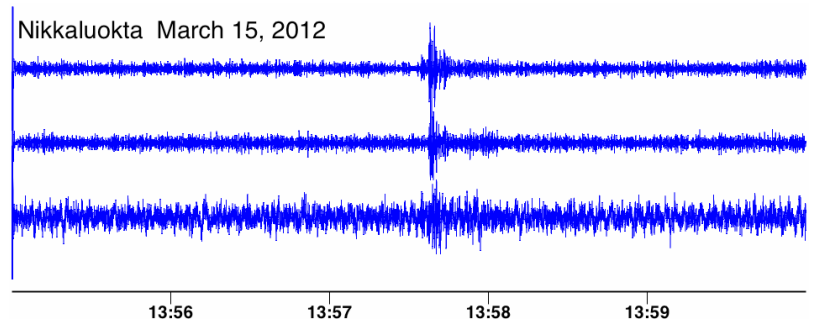

Figure 5. Registrations at the Nikkaluokta (NIK) seismograph station in Kiruna, Sweden at the moment when the Hercules aircraft disappeared from the airport radar screen. The signals arriving at 13:57:40 (UTC) fit well with the time when the communication between the aircraft and Kiruna airport traffic control was lost.

to a better physical understanding of the crash.

\subsection{September $11^{\text {th }}, 2001$ Terrorist Attacks on New York and Washington DC}

The "weapons" in these cases were commercial air- craft piloted by terrorists, who steered them into the Twin Towers buildings in New York city and into the Pentagon in Washington DC. In a third attempt, the terrorists lost control over their hijacked aircraft, and crashed in the Pennsylvania countryside. These air crashes were well recorded by stations being part of the New England seismograph network, and analysis results have been published [1].

\subsection{Other Notable Aircraft Accidents}

A Tupolev $154 \mathrm{M}$ commercial jet of Vnukovo Airlines crashed on August 29 ${ }^{\text {th }}, 1996$ near the Svalbard Airport, Longyearbyen, Norway. There were no eyewitnesses to the crash, but its site was easily located by the crew of a rescue helicopter an hour later. The timing of the crash was derived from analysis of records obtained from the nearby Spitsbergen seismic array.

The Swiss Air flight 111 from New York bound for Geneva on September $2^{\text {nd }}, 1998$ fatally crashed near St. 
Margaret's Bay, Nova Scotia. The aircraft broke up on impact in the sea, and most of the debris sank to the ocean floor at a depth of $55 \mathrm{~m}$. The crash site was easily located from eyewitness accounts, but the exact time of impact stemmed from analysis of seismic records at a nearby station of the Canadian National Network [11].

\section{MONITORING MARITIME DISASTERS}

Most accidents at sea are caused by collisions and stormy weather. Few of these accidents result in seismic imprints from a sinking ship, but some notable exceptions will be mentioned here. Most famous is the disaster of the Russian nuclear submarine Kursk in the Barents Sea on August $12^{\text {th }}, 2000$. Preparing to fire a torpedo using a hydrogen peroxide propellant, something went wrong, and the ensuing explosion within the hull was equivalent to 100 - $250 \mathrm{~kg}$ TNT. A few minutes later, other torpedo warheads exploded, and wrecked the submarine. Seismic signals from these explosions were recorded in Finland and Norway. The first explosion gave a signal magnitude of 2.2, while the second was stronger with magnitude estimates between 3.5 and 4.4 [2,12-14]. Initially little information on this accident was made available to media by Russian officials, so most information on location and the mentioned multiple explosions stemmed from seismological record analysis.

The cargo ship M/S Rocknes capsized on January $19^{\text {th }}$, 2004 in Vatlestraumen near Bergen, Norway, and 18 sailors perished even though the ship did not sink. When the ship touched an underwater reef, its bottom was ripped open, and water poured into the cargo compartments. The ship capsized, and quickly emptied its cargo of coarse gravel. Strong seismic signals were recorded by nearby seismic stations. These were initially interpreted as the ship impacting on a reef. However, that explanation was untenable, since it implied that the ship's Mayday signals were sent prior to grounding. A more careful screening of the seismic records of the closest station, which was only $3 \mathrm{~km}$ away, revealed a weak signal preceding the later, strong ones. The former was the grounding signal, while the later ones were bubble pulses generated by air pockets escaping from the holds. In the final report on this shipwreck report, the official grounding time was that of the seismic recording.

When the M/S Estonia sank on the Tallinn-Stockholm route on September $28^{\text {th }}, 1994$, in stormy weather in the Baltic Sea, more than 850 passengers and crewmembers perished. It was rumored that an explosion inside the hull caused the disaster, albeit the official investigation concluded that the bow visor of the ferry was torn off, with subsequent flooding of the car deck. If an explosive device had caused the sinking, detectable seismic signals should have been emitted. However, no Finnish network station recordings could be associated with the M/S Estonia sinking, and the negative evidence supported the Investigation Commission's conclusion about the cause of the disaster.

\section{DISCUSSION}

Probably few authorities or news media would turn to seismologists for information in case of an airplane accident. Seismology may, however, play a key role in determining not only the nature of the crash, but it can also provide a fast site location if so desired. Albeit most airplane accidents are related to landing or take-off, often in foul weather, more than once rescue missions have been delayed for hours simply because the plane crash site was not immediately known. The advantage of seismic recordings in such cases is that only some small investigative efforts are needed for significantly limiting the search area for the wreckage. In the course of this study, we have read official disaster reports on fatal aircraft accidents, and these usually related the timing of the accident to the "origin time" as reported by seismologists. This parameter together with other information can help to track a planes' final course prior to impact. And socalled negative evidence in terms of weak or absent seismic recordings also may be helpful, as in the case of the Hercules accident at Mt. Kebenekaise or the M/S Estonia as, discussed above.

On February $15^{\text {th }} 2013$ a spectacular meteorite explosion shook the city of Chelyabinsk in NW Russia. The seismic signals beyond 1500 kilometers could be connected to the meteorite burst. The same applied to far away infrasound recordings in northern Greenland as monitored by international monitoring system (IMS) of the Comprehensive Test Ban Treaty Organization (CTBTO) in Vienna, Austria

\section{CONCLUSIONS}

We analyzed here two aircraft accidents with Registered seismic data stemming from the impact of the aircraft on the ground. Also, some other well-documented accidents, which generated clear seismic signals, were mentioned and some details are discussed.

Seismic data may provide information about large motor vehicle, aircraft, car/lorry or ship accidents. Such recordings can be used to simulate the final stages of such accident, by providing information on the object's terminal speed, type and site of impact and so forth. Combined with information from in situ investigations this would add credence to usefulness of seismic data in such cases.

\section{ACKNOWLEDGEMENTS}

We express our gratitude to Dr. Dieter Reidel, Ottawa, Canada for his extensive language help. Also the reviewers' comments of the manu- 
script are highly appreciated. Help of the Finnish Air Force for providing the data of the last moments of Hornet is seen essential to model the terminal stages of the fighter.

\section{REFERENCES}

[1] Kim, W.-Y., Sykes, L.R., Armitage, J.H., Xie, J.K., Jacob, K.H., Richards, P.G., West, M., Waldhauser, F., Armbruster, J., Seeber, L., Du, W.X. and Lerner-Lam, A. (2001) Seismic waves generated by aircraft impacts and building collapses at World Trade Center, New York City. Eos, Transactions American Geophysical Union, 82, 570-571. doi:10.1029/01EO00330

[2] Koper, K.D., Wallace, T.C., Taylor, S.R. and Hartse, H.E. (2001) Forensic seismology and the sinking of the Kursk, Transactions American Geophysical Union, 82, 37-46. doi:10.1029/01EO00023

[3] Husebye, E.S. (2008) Earthquake monitoring and seismic hazard mitigation in Balkan countries. Springer Science Verlag, Berlin. doi:10.1007/978-1-4020-6815-7

[4] Kim, W.-Y. (1998) The ML scale in eastern North America. Bulletin of the Seismological Society of America, 88, 935-951.

[5] Ringdal, F., Marshall, P.D. and Alewine R.W. (1992) Seismic yield determination of soviet underground nuclear explosions at the Shagan River test site. Geophysical Journal International, 109, 65-77. doi:10.1111/j.1365-246X.1992.tb00079.x

[6] Pomeroy, P.W. (1963) Long period seismic waves from large near-surface nuclear explosions. Bulletin of the Seismological Society of America, 53, 109-149.
[7] McGarr, A., Latham, G.V. and Gault, D.E. (1969) Meteoroid impacts as sources of seismicity on the Moon. Journal of Geophysical Research, 25, 5981-5994. doi:10.1029/JB074i025p05981

[8] Latham, G.V., McDonald W.G. and Moore, H.J. (1970) Missile impacts as sources of seismic energy on the Moon. Science, 168, 242. doi: $10.1126 /$ science. 168.3928 .242

[9] Dahl, J.M. and Schultz, P.H. (2001) Measurement of stress wave asymmetries in hypervelocity projectile impact experiments. International Journal of Impact Engineering, 26, 1-10. doi:10.1016/S0734-743X(01)00077-X

[10] Diarienr M-04/12 (2012) Preliminary compilation of facts regarding the accident on 15 March 2012 of an aircraft of type C-130J Super Hercules, registration number 5630 of the Norwegian Air Force, at Mount Kebnekaise, in the county of Norbotten. Swedish Accident Investigation Authority, Stockholm.

[11] McCormack, D.A. (2003) Using seismic data in air crash investigations. CTBTO Spectrum, Vienna, 2, 16.

[12] Ringdal, F., Kværna, T. and Paulsen, B. (2000) Seismic events in the Barents Sea at and near the site of the Kursk submarine accident on 12 August 2000. NORSAR Science Report 1-2000/2002, Kjeller, 77-88.

[13] Tarvainen, M. (2001) Monitoring underwater explosionscase Kursk. Geophysics Days in 2001, Helsinki (in Finnish with English abstract).

[14] Savage, B. and Helmberger, D.V. (2001) Kursk explosion. Bulletin of the Seismological Society of America, 91, 753759. doi:10.1785/0120000295 